\title{
PENGARUH MOTIVASI INTRISIK,KEDISIPLINAN, GAYA KEPEMIMPINAN DEMOKRATIS, KOMITMEN NORMATIF TERHADAP KEPUASAN KERJA KARYAWAN PG. SUMBERHARJO PEMALANG \\ Wiwit Murfitriana \\ Universitas Muhammadiyah Purwokerto
}

Hengky Widhiandono

Universitas Muhammadiyah Purwokerto

\begin{abstract}
Abstack
Penelitian ini bertujuan untuk mengetahui pengaruh motivasi intrinsik, kedisiplinan, gaya kepemimpinan demokratis, komitmen normatif baik secara persial maupun simultan. Metode yang digunakan dalam penelitian ini adalah metode random sampling, yaitu dengan menggunakancara teknik pengundian,dengan kriteria karyawan tetap yang berjumlah 317 dengan sampel 77. Metode analisis yang digunakan adalah uji regresi berganda dengan tingkat signifikan $(\alpha) 0,05$, dengan uji t dan uji $F$ untuk menguji hipotesis.
\end{abstract}

Hasil penelitian ini menyimpulkan bahwa motivasi intrinsik, komitmen normatif secara parsial tidak berpengaruh signifikan terhadap kepuasan kerja karyawan. Kedisiplinan, gaya kepemimpinan demokratis secara parsial berpengaruh signifikan terhadap kepuasan kerja karyawan. Motifasi intrinsik, kedisiplinan, gaya kepemimpinan demokratis, komitmen normatif secara simultan berpengaruh terhadap kepuasan kerja karyawan.

Kata kunci: Motivasi intrinsik, kedisiplinan, gaya kepemimpinan demokratis, komitmen normatif dan kepuasan kerja.

The research was aimed to know the effect of intrinsic motifation,disciplinary, democratic leading style, normative commitment either partially or simultaneously. The method used in this research was sampling random, that was by using prizing, with the fix employee criteria of 317 with 77 samples. The analysis method used was double regression test with the significant level ( $\alpha$ ) 0,05, using the $t$ and $f$ test to test the hypothesis.

The result of the research concluded that intrinsic motivation, normative commitment in partial didn't affect significantly towards the employees' work satisfaction. Disciplinary, democratic leading style, normative commitment in partial affected significantly towards the employees' work satisfaction. Intrinsic motifation, disciplinary, democratic leading style, normative commitment either partially or simultaneously towards the employees' work satisfaction.

Key word : Intrinsic motifation, disciplinary, democratic leading style, normative

PG. Sumberharjo merupakan salah satu perusahaan yang bergerak di bidang produksi. Unit produksi yang dikelola oleh PG. Sumberharjo yang terletak di Kecamatan Pemalang adalah gula pasir. Pada musim giling, pabrik gula membutuhkan banyak sekali tenaga kerja, baik di kebun sebagai tenaga tebang, sopir truk yang mengangkut tebu dari kebun ke lokasi pabrik, tenaga produksi, tenaga pembantu produksi maupun tenaga pengangkut gula dari gudang ke truk. 
PG. Sumberharjo merupakan Badan Usaha Milik Negara yang tergabung dalam lingkungan PT. Perkebunan Nusantara IX (Persero) dan berada di bawah Administratur yang dibantu oleh Kepala Bagian Tanaman, Kepala Bagian Instalasi, Kepala Bagian Pengolahan dan Kepala Bagian Administrasi Keuangan dan Umum. Seorang Administrasi bertanggung jawab kepada Direksi Utama.

Kepuasan kerja adalah sikap emosional yang menyenangkan dan mencintai pekerjaannya, sikap ini dicerminkan oleh moral kerja, kedisiplinan dan prestasi kerja (Hasibuan, 2001). Kepuasan kerja dinikmati dalam pekerjaan, luar pekerjaan, dan kombinasi dalam dan luar pekerjaan.

Motivasi intrinsik yaitu motivasi yang berfungsi tanpa adanya rangsangan dari luar, dalam diri individu sudah ada suatu dorongan untuk melakukan suatu tindakan. Berbagai kebutuhan, keinginan dan harapan yang terdapat dalam diri pribadi seseorang menyusun motivasi internal orang tersebut (Handoko, 2001)

Disiplin adalah setiap perseorangan dan juga kelompok yang menjamin adanya kepatuhan terhadap perintah " dan berinisiatif untuk melakukan suatu tindakan yang diperlukan seandainya tidak ada printah “ (Heidjrachman dan Husnan, 2002).

Gaya kepemimpinan demokratis mendeskripsikan pemimpin yang cenderung mengikutsertakan karyawan dalam mengambil keputusan, mendelegasikan kekuasaan, mendorong partisipasi karyawan dalam menentukan bagaimana metode kerja dan tujuan yang ingin dicapai, dan memandang umpan balik sebagai suatu kesempatan untuk melatih karyawan (Robbins dan Coulter, 2002)

Komitmen normatif merupakan perasaan wajib sebagai karyawan untuk tetap mempertahankan organisasi tersebut karena merasa hutang ubdi (Meyer dan Alen, 1990 dalam Purwanto, 2010)

Masalah kepuasan kerja telah diteliti oleh beberapa peneliti dengan hasil variabel yang signifikan yaitu : variabel motivasi, lingkungan kerja, keinginan dan harapan, kebutuhan (Prabu,2005), variabel kedisiplinan, motivasi kerja, komitmen organisasi (Mamik, 2009), variabel imbalan dan gaya kepemimpinan (Ruvendi, 2005). Dari ketiga penelitian tersebut terdapat beberapa kelemahan penelitian yaitu yang dilakukan oleh Prabu (2005) karena mempunyai nilai $\mathrm{R}^{2}$ yang kecil, sehingga untuk meningkatkan $\mathrm{R}^{2}$ maka penelitian ini akan menambah variabel imbalan dan gaya kepemimpinan yang telah diteliti oleh Ruvendi (2005) agar nilai $\mathrm{R}^{2}$ meningkat. Perbedaan lain dengan penelitian terdahulu yaitu pada penelitian yang dilakukan oleh Mamik meneliti tentang pengaruh kedisiplinan, motivasi kerja, dan komitmen organisasi terhadap kepuasan kerja karyawan. Sedangkan pada penelitian ini akan mencoba meneliti mengenai pengaruh motivasi intrinsik, kedisiplinan, gaya kepemimpinan demokratis, komitmen normatif, terhadap kepuasan kerja karyawan.

Berdasarkan uraian latar belakang diatas, maka penelitian ini mengambil judul “

\section{PENGARUH MOTIVASI INTRINSIK, KEDISIPLINAN, GAYA KEPEMIMPINAN DEMOKRATIS, KOMITMEN NORMATIF TERHADAP KEPUASAN KERJA KARYAWAN PG.SUMBERAHARJO PEMALANG.}

Tujuan penelitian ini untuk (1) menganalisis pengaruh motivasi intrinsik secara parsial terhadap kepuasan kerja (2) menganalisis pengaruh kedisiplinan secara parsial terhadap kepuasan kerja (3) menganalisis pengaruh gaya kepemimpinan demokratis secara parsial terhadap kepuasan kerja (4) untuk menganalisis pengaruh komitmen normatif secara parsial terhadap kepuasan kerja (5) untuk menganalisis pengaruh motivasi intrinsik, kedisiplinan, gaya kepemimpinan demokratis dan komitmen normatif secara simultan terhadap kepuasan kerja karyawan. 


\section{A. Perumusan Masalah}

Berdasarkan Latar belakang masalah dan uraian diatas, dapat dirumuskan beberapa permasalahan sebagai berikut :

1. Apakah motivasi intrinsik mempunyai pengaruh secara parsial terhadap kepuasan kerja?

2. Apakah kedisiplinan mempunyai pengaruh secara parsial terhadap kepuasan kerja?

3. Apakah gaya kepemimpinan demokratis mempunyai pengaruh secara parsial terhadap kepuasan kerja?

4. Apakah komitmen normatif mempunyai pengaruh secara parsial terhadap kepuasan kerja?

5. Apakah motivasi intrinsik kedisiplinan, gaya kepemimpinan demokratis dan komitmen normatif berpengaruh secara simultan terhadap kepuasan kerja?

\section{B. Pembatasan Masalah}

1. Responden adalah seluruh karyawan PG. Sumberharjo Pemalang

2. Lokasi penelitian berada di PG. Sumberharjo Pemalang

3. Penelitian ini dibatasi pada motivasi intrinsik, kedisiplinan, gaya kepemimpinan demokratis dan komitmen normatif terhadap kepuasan kerja karyawan PG.Sumberharjo Pemalang

\section{Kerangka Pemikiran}

Dari hasil penelitian terdahulu, maka yang menjadi variabel-variabel didalam penelitian ini adalah motivasi intrinsik, kedisiplinan, gaya kepemimpinan demokratis, komitmen normatif sebagai variabel independen dan kepuasan kerja sebagai variabel dependen. Sehingga kerangka pemikiran dapat dilihat pada sebagai berikut :

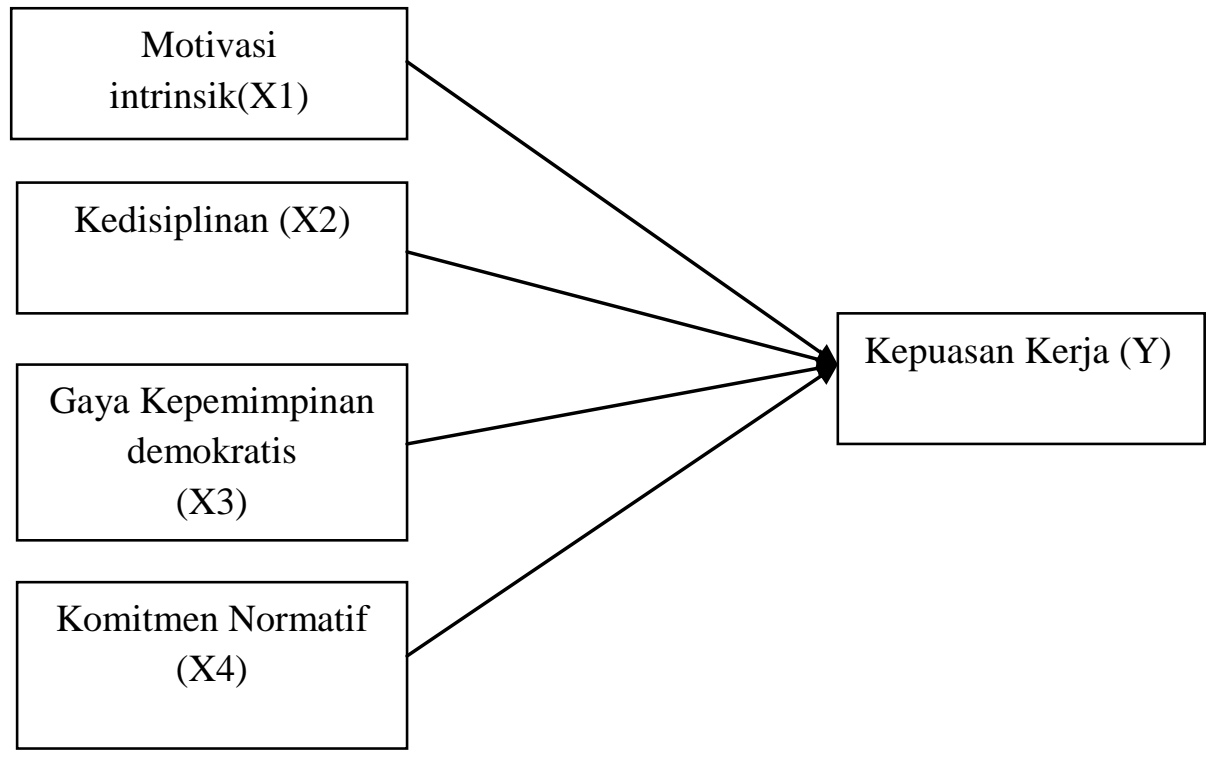




\section{Hipotesis}

Berdasarkan penelitian yang ingin dicapai dan didasari oleh landasan teori yang telah diuraikan maka hipotesis dalam penelitian ini adalah :

1. Motivasi intrinsik secara parsial berpengaruh terhadap Kepuasan kerja pada PG. Sumberharjo.

2. Kedisiplinan secara parsial berpengaruh terhadap Kepuasan kerja pada PG. Sumberharjo.

3. Gaya kepemimpinan demokratis parsial berpengaruh terhadap Kepuasan kerja pada PG. Sumberharjo.

4. Komitmen normatif secara parsial berpengaruh terhadap Kepuasan kerja pada PG. Sumberharjo.

5. Motivasi intrinsik, kedisiplinan, gaya kepemimpinan demokratis, dan Komitmen normatif secara simultan berpengaruh terhadap Kepuasan kerja pada PG. Sumberharjo.

\section{METODE PENELITIAN ANALISIS DATA}

A. Metodologi Penelitian

\section{Jenis Penelitian}

Jenis penelitian yang digunakan dalam penelitian ini adalah metode survey yaitu penelitian yang mengambil sample dari satu populasi dan menggunakan kuesioner sebagai alat pengumpul data yang pokok. Survey merupakan studi yang bersifat kuantitatif yang digunakan untuk meneliti gejala suatu kelompok atau perilaku individu pada survey tidak ada intervensi. Survey mengumpulkan informasi dari tindakan seseorang, pengetahuan, kemauan, pendapat, perilaku dan nilai. Penggalian data dapat melalui kuesioner, wawancara, observasi, maupun data dokumen (Singarimbun, 1998).

\section{Populasi dan Sample}

Jumlah sampel penelitian adalah sebanyak 77 responden dari populasi 317 karyawan di PG. Sumberharjo Pemalang.

Jumlah sampel (Size of Sampel) ditentukan berdasarkan pada perhitungan dari rumus Slovin dengan tingkat kesalahan yang ditoleransi sebesar 10\%

$$
n=\frac{N}{\left.1+[N(E)]^{2}\right]}
$$

\section{Dimana}

n : Ukuran Sampel

N : Ukuran Populasi

E : Margin of error (kesalahan) yang masih dapat diterima sebesar 10\% atau 0,1

Dengan menggunakan rumus diatas maka akan diperoleh jumlah sampel sebanyak 77 responden.

$n=\frac{N}{1+\left[N(e)^{2}\right]}$

$$
n=\frac{317}{1+\left[317(0,1)^{2}\right]}
$$

$\mathrm{n}=76,02$ dinaikan menjadi 77 responden. 


\section{Metode Pengumpulan Data}

a. Data Primer

Pengumpulan data primer yaitu hasil wawancara atau hasil pengisian kuesioner yang diperoleh dari para karyawan PG. Sumberharjo di Pemalang.

1. Wawancara

2. Observasi

3. Kuesioner

b. Data Sekunder

Data sekunder yaitu data jumlah karyawan tetap, atau catatan yang diperoleh dari PG. Sumberharjo yang dapat mendukung dalam memperdalam dan mempertajam analisis pembahasan hasil penelitian.

\section{Devinisi Oprasional Variabel}

\section{a. Variabel Bebas $(\mathrm{X})$}

1). Motivasi Intrinsik(X1)

Motivasi intrinsik yaitu motivasi yang berfungsi tanpa adanya rangsangan dari luar, dalam diri individu sudah ada suatu dorongan untuk melakukan tindakan. Berbagai kebutuhan, keinginan dan harapan yang terdapat dalam diri pribadi seseorang menyusun motivasi internal orang tersebut (Handoko, 2001).

Indikator Motivasi Intrinsik menurut (Ganesan dan Weitz, 1996)

a. Adanya sikap peduli terhadap pekerjakan.

b. Menyukai pekerjaan yang menantang.

c. Selalu merasa senang terhadap pekerjaannya.

d. Menunjukkan sikap setia terhadap pekerjaannya walaupun menantang.

e. Menunjukan sikap keterkaitan dengan pekerjaan.

f. Adanya kesempatan untuk belajar sesuatu yang berbeda dari pekerjaan

2). Kedisiplinan

Disiplin adalah tindakan manajemen untuk memberikan semangat kepada pelaksanaan standar organisasi, ini adalah pelatihan yang mengarah pada upaya membenarkan dan melibatkan pengetahuan-pengetahuan sikap dan perilaku pegawai untuk menuju pada kerjasama dan prestasi yang lebih baik (Davis, 2002). organisasi.

Indikator-indikator yang mempengaruhi tingkat kedisiplinan karyawan suatu

a) Tujuan dan Kemampuan

Tujuan yang harus dicapai jelas dan ditetapkan secara ideal serta cukup menantang bagi kemampuan karyawan yang bersangkutan agar bekerja sungguh-sungguh dan disiplin dalam mengerjakannya.

b) Teladan Pimpinan

Ataeladan pimpinan sangat berperan dalam menentukan kedisiplinan karyawan karena pimpinan menjadi teladan dan panutan bagi bawahannya.

c) Balas Jasa 
Untuk mewujudkan kedisiplinan karyawan yang baik, perusahaan harus memberikan balas jasa yang relatif besar.

d) Keadilan

Keadilan ikut mendorong terwujudnya kedisiplinan karyawan, karena ego dan sifat manusia yang selalu merasa dirinya penting dan minta diperlakukan sama dengan manusia lainnya.

e) Sanksi Hukum

Sanksi hukum berperan penting dalam pemeliharaan kedisiplinan karyawan

3). Gaya Kepemimpinan Demokratis

Gaya kepemimpinan demokratis mendeskripsikan pemimpin yang cenderung mengikut sertakan karyawan dalam mengambil keputusan, mendelegasikan kekuasaan, mendorong partisipasi karyawan dalam menentukan bagaimana metode kerja dan tujuan yang ingin dicapai, dan memandang umpan balik sebagai suatu kesempatan untuk melatih karyawan (Robbins dan Coutler, 2002).

Indikator Gaya kepemimpinan demokratis (Robbins dan Coutler, 2002).

a) Pemimpin selalu mengikutsertakan karyawan

b) Partisipasi karyawan

c) Pendelegasian kekuasaan

d) Pemimpin selalu memberikan kesempatan untuk melatih karyawan

4). Komitmen Normatif

Meyer dan Alen (1990) (dalam Purwanto 2010) mengemukakan komitmen ini adalah komitmen berdasarkan perasaan wajib sebagai anggota atau karyawan untuk tetap tinggal karena perasaan hutang budi.

Indikator komitmen normatif (Allen dan Mayer, 2000) :

a) Mempunyai perasaan yang berkewajiban

b) Merupakan ukuran seberapa besar perasaan tanggung jawab karyawan terhadap organisasi

c) Bertahan dalam perusahaan

\section{b. Variabel Dependen (Y) adalah kepuasan kerja}

Kepuasan kerja merupakan suatu sikap umum terhadap pekerjaan seseorang, selisih antara banyaknya ganjaran yang diterima seorang pegawai dan banyaknya yang mereka yakini apa yang seharusnya mereka terima (Robbis, 1996).

Penelitian dari Spector (dalam Yuwono, 2005) mendefinisikan indikator kepuasan kerja dari sembilan aspek yaitu :

1) Upah

2) Promosi

3) Supervisi

4) Benefit

5) Contingent

6) Operating procedures

7) Coworkers

8) Natur of work

\section{B. Metode Analisis Data}

\section{Skoring}


Dalam penelitian ini menggunakan skala likert. Skala ini umumnya berisi bagian skala terhadap semua pertanyaan-pertanyaan yang ditunjukan peneliti dalam kuesioner.

Model skala likertdigunakan dengan 5 jawaban yaitu:

SS : : Sangat Seutuju dengan skor 5

$\mathrm{S} \quad$ : Setuju dengan skor 4

$\mathrm{R} \quad$ : Ragu-ragu dengan skor 3

TS : Tidak Setuju dengan skor 2

STS : Sangat Tidak Setuju dengan skor 1

\section{Uji Kualitas Data}

a. Uji Validitas

Uji validitas digunakan untuk mengukur sah atau valid tidaknya suatu kuisioner (Ghozali, 20010. Dalam penelitian ini untuk menguji validitas kuisioner digunakan rumus teknik korelasi product momen(Singarimbun \& Effendi, 1998).

$$
r x y=\frac{\mathrm{N} \Sigma \mathrm{xy}-(\Sigma \mathrm{x})(\Sigma \mathrm{y})}{\sqrt{\left\{\mathrm{N} \Sigma \mathrm{x}^{2}-(\Sigma \mathrm{x})^{2}\right\}}\left(\mathrm{N} \Sigma \mathrm{y}^{2}-(\Sigma \mathrm{y})^{2}\right\}}
$$

Keterangan :

$\mathrm{r}=$ korelasi

$\mathrm{X}=$ skor pertanyaan ke $-\mathrm{N}$

$\mathrm{Y}=$ Skor total

$\mathrm{N}=$ jumlah responden

$\mathrm{XY}=$ skor pernyataan ke-N dikalikan skor total

b. Uji Reabilitas

Uji reabilitas adalah mengukur suatu kuesioner yang merupakan indikator dari variabel atau konstruk. Suatu kuesioner dikatakan reliabel atau stabil dari waktu ke waktu. Suatu konstruk atau variabel dikatakan reliabel jika memberikan nilai Cronbach Alpha > 0,06 (Nunnaily, 1967 dalam Ghozali, 2005).

\section{Analisis dan Pembuktian Hipotesis}

a. Analisis Regresi Linier Berganda

Metode ini digunakan untuk menjelaskan pengaruh variabel bebas terhadap variabel terkait dengan membuat persamaan garis regresi linier berganda. Persamaan model regresi berganda menurut 9Awat, 1995) adalah : $\mathrm{Y}=\mathrm{a}+\beta 1 \mathrm{X} 1+\beta 2 \mathrm{X} 2+\beta 3 \mathrm{X} 3+\beta 4 \mathrm{X} 4+\mathrm{e}$

Keterangan :

$\mathrm{Y}=$ Kepuasan Kerja

A $\quad=$ Konstanta

$\mathrm{X} 1=$ Motivasi Intrinsik

$\mathrm{X} 2 \quad=$ Kedisiplinan

X3 = Gaya Kepemimpinan Demokratis

X4 = Komitmen Normatif

B1- $\beta 4=$ Intercept/Koefisien Regresi

e $\quad=$ Standar Error

b. Uji Asumsi Klasik

1) Pengujian Normalitas 
Pengujian ini dimaksudkan untuk menguji apakah dalam sebuah model regresi tersebut variabel dependen, variabel independen, atau keduanya berdistribusi normal atau tidak yaitu digunakan uji Kolmogorov-Smimov. Penguji ini dilakukan denganmenggunakan SPSS for windows. Data dikatakan berdistribusi normal jika signifikasi lebih besar dari 5\% atau 0,05 (Ghozali, 2007).

2) Penguji Gejala Multikolinieritas

Uji multikolinieritas bertujuan untuk menguji apakah model regresi ditemukan adanya kolerasi antar variabel bebas (independen). Model regresi yang baik seharusnya tidak terjadi kolerasi diantara variabel independen. Jika variabel independen saling berkolerasi, maka variabelvariabel ini tidak orthogonal. Variabel orthogonal adalah variabel independen yang nilai kolerasi antara sesama variabel independen sama dengan nol. Untuk mendeteksi di dalam model regresi nilai $\mathrm{R}^{2}$ yang dihasilkan oleh suatu estimasi model regresi adalah sebagai berikut:

a) Nilai $\mathrm{R}^{2}$ yang menghasilkan oleh suatu empiris sangat tinggi, tetapi secara individual variabel-variabel independen banyak yang tidak signifikan terhadap variabel dependen.

b) Menganalisis matrik korelasi variabel-variabel independen. Jika antar variabel independen ada korelasi yang cukup tinggi (umumnya diatas 0.09), maka hal ini merupakan indikasi adanya multikolonieritas.

c) Multikolinieritas dapat juga dilihat dari (1) nilai tolerance dan lawannya (2) variance inflation factor (VIF). Kedua ukuran ini menunjukan setiap variabel independen manakah yang dijelaskan oleh variabel independen lainnya. Dalam pengertian sederhana setiap variabel independen menjadi variabel dependen (terikat) dan regres terhadap variabel lainnya. Tolerance mengukur variabel independen yang terpilih tidak dijelaskan oleh variabel independen lainnya. Jadi nilai tolerance yang rendah sama dengan nilai VIF tinggi (karena VIF -1/Tolerance). Nilai cutoff yang umum dipakai untuk menunjukan adanya multikolonieritas adalah nilai tolerance $\leq 0.01$ atau sama dengan nilai VIF $\geq 10$. Setiap peneliti harus menentukan tingkat kolonieritas yang masih dapat ditolerir. Sebagai contoh nilai tolerance $=0.01$ sama dengan tingkat kplonearitas 0.95. Walaupun multikolonieritas dapat di deteksi dengan nilai Tolerance dan VIF, tetapi kita masih tetap tidak mengetahui variabel-variabel independen mana sajakah yang saling berkolerasi (Ghozali, 2007).

3) Pengujian Heteroskedastisitas

Heteroskedastisitas bertujuan untuk menguji apakah dalam model regresi terjadi ketidaksamaan variance dari residual dari satu pengamatan ke pengamatan yang lain. Untuk mendeteksi adanya gejala heteroskedastisitas, yaitu ada atau tidaknya pola yang terjadi pada nilai residu pada model dalam penelitian ini menggunakan uji glejser, dengan menghitung efisiensi regresi dari masing-masing variabel independen terhadap nilai absolut residunya (e), jika ini probabilitasnya lebih besar dari nilai alpha $(0,05)$, maka dapat dipastikan model tidak mengandung unsur heteroskedastisitas (Ghozali, 2007).

c. $\quad$ Jji F 
Tujuan uji $\mathrm{F}$ adalah untuk mengetahui derajat signifikan hubungan variabel-variabel independen Motivasi Intrinsik (X1), Kedisiplinan (X2), Gaya kepemimpinan Demokratis (X3), dan Komitmen Normatif (X4) secara bersama-sama berpengaruh terhadap variabel dependen Kepuasan kerja (Y)

Uji $F$ dengan cronbach alpha 0,05 atau 95\%, menggunakan rumus (Algifari, 2000).

$F=\frac{\mathrm{R}^{2} /(\mathrm{k}-1)}{\left(1-R^{2}\right) /(n-k-1)}$

Keterangan:

$\mathrm{F}=$ Nilai $\mathrm{F}$ hitung

$\mathrm{R}^{2}=$ Koefisien determinasi

$\mathrm{K}$ = Jumlah variabel bebas

$\mathrm{n} \quad$ = Jumlah sampel

Rumus Hipotesis :

a. Ho:Bo=0 : Secara bersama-sama tidak terdapat pengaruh signifikan dari variabel (X1) Motivasi Intrinsik, (X2) Kedisiplinan, (X3) Gaya Kepemimpinan Demokratisw, (X4) Komitmen Norematif terhadap variabel kepuasan $\operatorname{kerja}(\mathrm{Y})$.

b. Ha:Bo $\neq 0$ : Secara bersama-sama terdapat pengaruh signifikan dari variabel (X1) Motivasi Intrinsik, (X2) Kedisiplinan, (X3) Gaya Kepemimpinan Demokratisw, (X4) Komitmen Norematif terhadap variabel kepuasan $\operatorname{kerja}(\mathrm{Y})$.

Kriteria Pengujian :

Ho ditolak jika Fhitung $>$ Ftabel

Ho diterima jika Fhitung $\leq$ Ftabel

d. Uji t

Untuk membuktikan pengujian apakah secara individual variabel independen yaitu pengaruh motivasi ekstrisik, kedisiplinan, gaya kepemimpinan demokratis, komitmen normatif, terhadap kepuasan kerja karyawan. Untuk menguji koefisien regresi linier berganda digunakan formulasi sebagai berikut:

$t=\frac{b i}{S b i}$

Keterangan :

$\mathrm{t} \quad=$ Nilai $\mathrm{t}$ hitung

bi $\quad=$ Koefisien regresi

Sbi = Kesalahan baku koefisien regresi atau standar deviasi

Rumusan hipotesis:

$\mathrm{Ho}: \mathrm{Bo}=0$ : Secara parsial tidak ada pengaruh yang berarti antara variabel variabel independen Motivasi Intrinsik (X1), Kedisiplinan (X2), Gaya Kepemimpinan Demokratis 
(X3),dan Komitmen Normatif (X4) secara bersama-sama berpengaruh terhadap variabel dependen Kepuasan Kerja (Y)

Ho:Bo $\neq 0$ : Secara parsial ada pengaruh yang berarti antara variabel variabel independen Motivasi Intrinsik (X1), Kedisiplinan (X2), Gaya Kepemimpinan Demokratis (X3),dan Komitmen Normatif (X4) secara bersama-sama berpengaruh terhadap variabel dependen Kepuasan Kerja (Y)

Kriteria Pengujian :

Ho ditolak jika thitung > ttabel atau thitung <- ttabel

Ho diterima jika - ttabel $\leq$ thitung $\leq$ ttabel

\section{HASIL DAN PEMBAHASAN}

\section{1) Hasil Pengukuran Variabel}

Untuk mengetahui hasil pengukuran variabel dapat dilihat pada nilai mean, dengan kategori tinggi apabila mean $\geq 3,5$ yaitu $(5 \times 70 \%)$, dan kategori rendah apabila mean $<3,5$. Hasil pengukuran variabel dapat dilihat pada tabel

\section{Tabel Hasil Pengukuran Variabel}

\begin{tabular}{|l|l|l|l|}
\hline Variabel & N & Mean & Nilai \\
\hline Motivasi Intrinsik & 77 & 3.8701 & Tinggi \\
Kedisiplinan Kepemimpinan & 77 & 3.8416 & Tinggi \\
Gaya & 77 & 3.5351 & Tinggi \\
Demokratis & 77 & 3.6632 & Tinggi \\
Komitmen Normatif & 77 & 3.3273 & Rendah \\
Kepuasan Kerja & 77 & & \\
Valid N (listwise) & & & \\
\hline
\end{tabular}

Berdasarkan tabel diketahui bahwa variabel motivasi intrinsik, kedisiplinan, gaya kepemimpinan demokratis, komitmen normatif mempunyai nilai mean yang tinggi yaitu $\geq 3,5$ sedangkan variabel kepuasan kerja mempunyai nilai mean yang rendah yaitu $<3,5$.

\section{2) Regresi Linier Berganda}

Untuk mengetahui seberapa besar pengaruh motivasi intrinsik, kedisiplinan, gaya kepemimpinan demokratis dan komitmen normatif, terhadap kepuasan kerja karyawan dapat dilakukan dengan uji regresi linier berganda. Hasil uji regresi linier berganda dapat dilihat dalam tabel 4 .

Tabel Hasil Uji Regresi Linier Berganda

\begin{tabular}{|c|c|c|c|c|c|}
\hline \multirow{2}{*}{ Model } & \multicolumn{2}{|c|}{$\begin{array}{c}\text { Unstandardized } \\
\text { Coefficients }\end{array}$} & $\begin{array}{c}\text { Standardized } \\
\text { Coefficients }\end{array}$ & t & Sig. \\
\cline { 2 - 4 } & $\mathrm{B}$ & $\begin{array}{c}\text { Std. } \\
\text { Error }\end{array}$ & Beta & & \\
\hline
\end{tabular}




\begin{tabular}{|l|l|l|l|l|l|}
\hline 1 (Constant) & .426 & .653 & & .653 & .516 \\
Motivasi Intrinsik & .079 & .100 & .081 & .789 & .433 \\
Kedisiplinan & .358 & .146 & .291 & 2.457 & .016 \\
Gaya Kepemimpinan & .321 & .105 & .366 & 3.055 & .003 \\
Demokratis & .023 & .136 & .016 & .166 & .869 \\
$\quad$ Komitmen Normatif & & & & & \\
\hline
\end{tabular}

a. Dependent Variable : Kepuasan Kerja

Berdasarkan tabel tersebut disusun persamaan regresi sebagai berikut :

$\mathrm{Y}=0,426+0,079 \mathrm{X} 1+0,358 \mathrm{X} 2+0,321 \mathrm{X} 3+0,023 \mathrm{X} 4$

Adapun interpretasi dari persamaan tersebut adalah:

$\alpha=0,426$ artinya berdasarkan persamaan regresi tersebut dapat diketahui bahwa jika variabel independen ada maka kepuasan kerja karyawan sebesar 0,426 satuan.

$\beta 1=0,079$ artinya setiap terjadi peningkatan motivasi intrinsik satu satuan maka akan terjadi kenaikan kepuasan kerja karyawan sebesar 0,079 satuan jika variabel independen yang lain tetap.

$\beta 2=0,358$ artinya setiap peningkatan kedisiplinan satu satuan maka akan terjadi kenaikan kepuasan kerja karyawan sebesar 0,358 satuan jika variabel independen yang lain tetap.

B3 $=0,321$ artinya setiap peningkatan kedisiplinan gaya kepemimpinan demokratis satu satuan maka akan terjadi kenaikan kepuasan kerja karyawan sebesar 0,321 satuan jika variabel independen yang lain tetap.

B4 $=0,023$ artinya setiap peningkatan komitmen normatif satu satuan maka akan terjadi kenaikan kepuasan kerja karyawan sebesar 0,023 satuan jika variabel independen yang lain tetap.

\section{3) Pengujian Hipotesis}

Model Summaryb

\begin{tabular}{|l|c|c|c|c|}
\hline Model & $\mathrm{R}$ & $\mathrm{R}$ Square & $\begin{array}{c}\text { Adjusted R } \\
\text { Square }\end{array}$ & $\begin{array}{c}\text { Std. Error of the } \\
\text { Estimate }\end{array}$ \\
\hline 1 & $.626 \mathrm{a}$ & .391 & .358 & .47872 \\
\hline
\end{tabular}

a. Predictor: (Constant), Komitmen Normatif, Kedisiplinan, Motivasi, Gaya Kepemimpinan Demokratis

b. Dependent Variable : Rata-rata Kepuasan Kerja

Nilai adjusted $\mathrm{R}^{2}$ sebesar $0,358(35,8 \%)$ hal ini berarti variabel motivasi intrinsik, kedisiplinan, gaya kepemimpinan demokratis, dan komitmen normatif mempengaruhi kepuasan kerja karyawan sebesar 35,8 \%, sedangkan sisanya sebesar $64,2 \%$ dipengaruhi oleh faktor lain yang tidak diteliti dalam penelitian ini.

\section{a. Hipotesis Pertama}

Variabel motivasi intrinsik memiliki nilai thitung sebesar 0,789 lebih kecil dari nilai ttabel sebesar 2,000 serta nilai signofikan $0,433>0,5$. Hal ini berarti motivasi intrinsik tidak berpengaruh signifikan secara parsial terhadap kepuasan kerja karyawan, dengan demikian hipotesis pertama ditolak. 


\section{b. Hipotesis Kedua}

Variabel kedisiplinan memiliki nilai thitung sebesar 2,457 lebih besar dari nilai ttabel sebesar 2,000 serta nilai signifikan 0,016>0,05. Hal ini berarti kedisiplinan berpengaruh signifikan secara parsial terhadap kepuasan kerja karyawan, dengan demikian hipotesis kedua diterima.

\section{c. Hipotesis Ketiga}

Variabel gaya kepemimpinan demokratis memiliki nilai thitung sebesar 3,055 lebih besar dari nilai ttabel sebesar 2,000 serta nilai signifikan 0,003>0,05. Hal ini berarti gaya kepemimpinan demokratis berpengaruh signifikan secara parsial terhadap kepuasan kerja karyawan, dengan demikian hipotesis ketiga diterima.

\section{d. Hipotesis Keempat}

Variabel komitmen normatif memiliki nilai thitung sebesar 0,166 lebih kecil dari nilai ttabel sebesar 2,000 serta nilai signifikan 0,869>0,05. Hal ini berarti komitmen normatif tidak berpengaruh signifikan secara parsial terhadap kepuasan kerja karyawan, dengan demikian hipotesis keempat ditolak.

e. Hipotesis Kelima

Untuk menguji pengaruh motivasi intrinsik, kedisiplinan, gaya kepemimpinan demokratis, dan komitmen normatif terhadap kepuasan kerja karyawan, menggunakan uji F. Hasil uji F dapat dilihat pada tabel

\begin{tabular}{|l|l|l|l|l|l|}
\hline Model & Sum of Squares & df & Mean Square & F & Sig. \\
\hline $\begin{array}{l}\text { 1 Regressio } \\
\text { N }\end{array}$ & 10.613 & 4 & 2.653 & 11.577 & $.000 \mathrm{a}$ \\
Residual & 16.500 & 72 & .229 & & \\
Total & 27.113 & 76 & & & \\
& & & & & \\
\hline
\end{tabular}

\section{ANOVAb}

a. Predictosr: (Constant), Komitmen Normatif, Kedisiplinan, Motivasi, Gaya Kepemimpinan Demokratis

b. Dependent Variable : Rata-rata Kepuasan Kerja

Berdasarkan tabel tersebut diketahui bahwa besarnya Fhitung sebesar 11.577 lebih besar dari nilai Ftabel sebesar 2.50 serta nilai signifikan 0,000 kurang dari 0.05. Dengan demikian motivasi intrinsik, kedisiplinan, gaya kepemimpinan demokratis, dan komitmen normatif secara simultan berpengaruh signifikan terhadap kepuasan kerja karyawan, sehingga hipotesis kelima diterima.

\section{PEMBAHASAN}

Motivasi intrinsik secara parsial tidak berpengaruh signifikan terhadap kepuasan kerja karyawan, ditunjukan dengan penguji hipotesisnya bahwa 
pengaruh motivasi intrinsik ditolak, berarti variabel motivasi intrinsik tidak mempengaruhi kepuasan kerja karyawan di PG. Sumberharjo hal tersebut disebabkan karena mereka yang bekerja di Perusahaan tersebut mempunyai keinginan dan harapan yang terdapat dalam diri pribadi seseorang, tetapi harapan tersebut belum terpenuhi sehingga motivasi intrinsik tidak mempengaruhi kepuasan kerja. Motivasi intrinsik mempunyai nilai tinggi sebesar 3,8 dikarenakan karyawan senang bekerja dan bisa menyelesaikan pekerjaan dengan baik. Motivasi intrinsik yaitu motivasi yang berfungsi tanpa adanya rangsangan dari luar, dalam diri individu sudah ada suatu dorongan untuk melakukan suatu tindakan (Handoko, 2009). Penelitian ini tidak sejalan dengan penelitian yang dilakukan oleh Mamik (2009), yang menyimpulkan bahwa motivasi kerja mempengaruhi kepuasan kerja karyawan.

Kedisiplinan secara parsial berpengaruh signifikan terhadap kepuasan kerja karyawan, ditunjukan dengan pengujian hipotesisnya bahwa pengaruh kedisiplinan diterima, kedisiplinan mempunyai nilai yang tinggi sebesar 3,8 karena peraturan yang diberikan telah sesuai dengan harapan karyawan, peraturan diciptakan agar pekerjaan dapat diselesaikan dengan baik, sehingga kedisiplinan dapat berjalan sesuai dengan yang di inginkan. Berarti variabel kedisiplinan mempengaruhi kepusan kerja karyawan di PG. Sumberharjo. Penelitian sejalan dengan yang dilakukan oleh Mamik (2009), yang menyimpulkan bahwa kedisiplinan mempengaruhi kepuasan kerja karyawan. Kedisiplinan merupakan sikap perseorangan dan juga kelompok yang menjamin adanya kepatuhan terhadap perintah" dan berinisiatif untuk melakukan suatu tindakan yang diperlukan seandainya tidak ada perintah".(Heidjrachman dan Husnan, 2002).

Gaya kepemimpinan demokratis secara parsial berpengaruh signifikan terhadap kepuasan kerja karyawan di PG. Sumberharjo, ditunjukan dengan pengujian hipotesisnya bahwagaya kepemimpinan demokratis diterima, gaya kepemimpinan demokratis mempunyai nilai tinggi sebesar 3,5 karena tipe gaya kepemimpinan telah sesuai dengan harapan karyawan, kepemimpinan berfungsi untuk mengarahkan karyawan, membimbing dan memberikan masukan terhadap keluhan karyawan dalam memperbaiki pekerjaan mereka. Penelitian ini sejalan dengan penelitian yang dilakukan oleh Ruvendi (2005) yang menyimpulkan bahwa gaya kepemimpinan mempengaruhi kepuasan kerja karyawan. Gaya kepemimpinan demokratis mendeskripsikan pemimpin yang cenderung mengikutsertakan karyawan dalam pemengambilan keputusan , mendelegasikan kekuasaan, mendorong partisipasi karyawan dalam menentukan bagaimana metode kerja dan tujuan yang ingin dicapai, dan memandang umpan balik sebagai suatu kesempatan untuk melatih karyawan (Robbins dan Coulter, 2002).

Komitmen normatif secara parsial tidak berpengaruh signifikan terhadap kepuasan kerja karyawan, ditunjukan dengan pengujian hipotesisnya bahwa komitmen normatif ditolak, komitmen normatif dikatakan tidak signifikan karena anda keinginan karyawan untuk meninggalkan atau berpindah pekerjaan ketempat lain untuk mencari penghasilan yang lebih baik. Hal ini berarti komitmen normatif tidak mempengaruhi kepuasan kerja karyawan di PG. Sumberharjo. Komitmen normatif mempunyai nilai tinggi sebesar 3,6 karena seseorang yang bekerja pada perusahaan tersebut merasa mempunyai hutang 
budi terhadap perusahaan yang telah memberikan lapangan kerja. Penelitian ini tidak sejalan dengan penelitian yang dilakukan oleh Mamik (2009) yang meyimpulkan bahwa komitmen organisasi mempengaruhi kepuasan kerja karyawan. Komitmen normatif merupakan perasaan wajib sebagai keryawan untuk tetap mempertahankan organisasi tersebut karena merasa hutang budi (Mayer dan Alen, 1990 dalam Purwanto, 2010).

\section{KESIMPULAN DAN SARAN}

\section{A. Kesimpulan}

Berdasarkan analisis yang telah dilakukan, maka ditarik beberapa kesimpulan, antara lain:

1. Motivasi intrinsik secara parsial tidak berpengaruh signifikan terhadap kepuasan kerja karyawan PG. Sumberharjo. Hal ini ditunjukan dengan nilai signifikan 0,433 lebih besar dari 0,05.

2. Kedisiplinan secara parsial berpengaruh signifikan terhadap kepuasan kerja karyawan PG. Sumberharjo. Hal ini ditunjukan dengan nilai signifikan 0,016 lebih kecil dari 0,05.

3. Gaya kepemimpinan demokratis secara parsial berpengaruh signifikan terhadap kepuasan kerja karyawan PG. Sumberharjo. Hal ini ditunjukan dengan nilai signifikan 0,003 lebih kecil dari 0,05.

4. Komitmen normatif secara parsial tidak berpengaruh signifikan terhadap kepuasan kerja karyawan PG. Sumberharjo. Hal ini ditunjukan dengan nilai signifikan 0,869 lebih besar dari 0,05.

5. Motivasi intrinsik, kedisiplinan, gaya kepemimpinan demokratis, komitmen normatif secara simultan berpengaruh signifikan terhadap kepuasan kerja karyawan PG. Sumberharjo. Hal ini ditunjukkan dengan nilai signifikan 0,000 lebih kecil dari 0,05.

\section{B. Saran}

Untuk lebih meningkatkan pengaruh positif terhadap kepuasan kerja karyawan secara maksimal pihak PG.Sumberharjo diharapkan :

1. Untuk meningkatkan motivasi intrinsik sebaiknya manajer memberikan dorongan terhadap karyawan untuk berdiskusi dan melakukan kerjasama dengan pimpinan, serta dapat memberikan support kepada karyawan dalam meningkatkan kepuasan kerja.

2. Unttuk meningkatkan kedisiplinan sebaiknya diadakan pengawasan kerja agar karyawan melaksanakan tugas sesuai peraturan yang berlaku dalam meningkatkan kepuasan kerja.

3. Untuk meningkatkan gaya kepemimpinan demokratis sebaiknya mengikutsertakan karyawan dalam pengambilan keputusan dan mendorong partisipasi karyawan dalam meningkatkan kepuasan kerja.

4. Untuk meningkatkan komitmen normatif sebaiknya memberikan kepercayaan terhadap karyawan agar karyawan menyadari bahwa bekerja di suatu perusahaan merupakan kewajiban moral dalam meningkatkan kepuasan kerja.

5. Bagi peneliti selanjutnya, sebaiknya menambah variabel lain selain motivasi intrinsik, kedisiplinan, gaya kepemimpinan demokratis dan komitmen normatif, misalnya variabel imbalan dalam jurnal (Ruvendi, 
2005), pengembangan karir dalam jurnal (Watimena, 2007) dan lingkungan kerja.

\section{DAFTAR PUSTAKA}

Agustina. Faktor-faktor Motivasi yang Mempengaruhi Kinerja Karyawan Pada PT Gaya Manunggal Kresitama.

Alle.M.1997. Psichology in Management. New York:McGraw-Hill Company.

Allen, N.J \& Meyer, J.P. 2000."Commitment in the workplace:Theory,Research, and application"'.California.

Algifari,2000.Analisis Regresi: Teori, Kasus, Solusi. Edisi Kedua. Yogyakarta:BPFE.

Andrew J. Durbin.2005. Pengaruh Gaya Kepemimpinan dan Kualitas Sumber Daya

Manusia terhadap Kinerja Kementrian Luar Negeri dan Kerjasama

Republik Demokratis Timor Leste di Dili, dalam Maria Jurnal Manajemen

Publik dan Bisnis.

As'ad,Moh.2002. Psikologi Industri, Seri Ilmu Sumber Daya Manusia.

Liberty:Yogyakarta

Awat, N.J.1995. Manajemen Keuangan . Jakarta:PT Gramedia Pustaka Utama.

Davis,Keith,2002. Fundamental Organisasi Behavior, Diterjemahkan Agus Dharma, Jakarta: Erlangga.

Ganesan. Shanker dan Barton A. Weiz.1996. "Impact Of Staffing Policies On Retail Buyer Job Attitudes And Behavior" Journal Of Betailing.

Ghozali. 2005. Aplikasi Analisis Multivariate dengan Program SPSS, Badan Penerbit

Universitas Diponegoro: Semarang.

. 2007. Model Persamaan Sitrukral Konsep dan Aplikasi dengan Program AMOS ver, 15.0. Badan Penerbit Universitas Diponegoro: Semarang.

Handoko, T Hani. 2001. Manajemen Personalia dan Sumber Daya Manusia. Edisi Kedua Cetakan ke 15 BPFE: Jakarta.

Hasibuan, 2001 : 202. Pengaruh Faktor Kepuasan Kerja terhadap Kinerja Karyawan. (digilib.Petra.ac.id)

.2009. Manajemen Sumber Daya Manusia. Edisi Kedua Cetakan ke 15 BPFE: Jakarta

. Melayu. S. P. 2009. Manajemen Sumber Daya Manusia Edisi Revisi. PT. Bumi Aksara: Jakarta

Herdrachman dan Husnan, Suad, 2002, Manajemen Personalia, BPFE-Yogyakarta.

Juniarti Indria, Ashari Bunnyanudin. 2006. Pengaruh Komitmen Organisasi dan Keterlibatan Kerja Islam Dengan Sikap Terhadap Perubahan Organisasi.

Mamik. 2008. Pengaruh Kedisiplinan, Motivasi Kerja, dan Komitmen Organisasi terhadap Kepuasan Kerja.

Muttaqiyathun. Ani. Pengaruh Kompensasi dan Lingkungan Kerja terhadap Kepuasan Kerja Karyawan. (Studi Kasus pada PT. Bank Perkreditan Rakyat Shinta Daya).

Nawawi, Hadari. 2001. Manajemen Sumber Daya Manusia. Cetakan keempat. Yogyakarta: Gadjah Mada University Press.

Prabu.2005. Pengaruh Lingkungan Kerja terhadap Kepuasan kerja pegawai Badan Koordinasi Keluarga Berencana Nasional Kabupaten Muara Enim. Vol.3.No.6.Desember.2005.

Purwanto. 2010. Pengaruh Komitmen Afektif, Komitmen Normatif, dan Komitmen Kontinuan, Terhadap Kepuasan Kerja Pada Karyawan Bagian Produksi 
PT Mitra Lestari Abdi Kecamatan Wangon. Skripsi. Universitas Muhammadiyah Purwokerto.

Robbins, Stephen P. 1996. Perilaku Organisasi konsep, Kontroversi, Aplikasi. Jakarta:

PT. Indeks Gramedia Grup.

.2008. Perilaku organisasi, Edisi 12 Salemba Empat: Jakarta.

Ruvendi. 2005. Imbalan dan Gaya Kepemimpinan Pengaruhnya Terhadap Kepuasan kerja Karyawan di Balai Besar Industri Hasil Pertanian Bogor.

Sarwoto Drs. 1979, Dasar-dasar Organisasi Manajemen, Ghalia Indonesia, Jakarta.

Singarimbun,Masri,dan Sofian Effendi. 1998. Metode Penelitian Survei. Jakarta: LP3ES.

Sopiah. 2008. Perilaku Organisasional, Penerbit Andi, Yogyakarta.

Sugiyono. 1999. Metode Penelitian Administrasi. Bandung:CV.Alvabeta.

Watimena, Abubakar, 2007. Pengaruh Motivasi, Perilaku Pemimpin dan Kesempatan

Pengembangan Karier Terhadap Kinerja Karyawan, Jurnal Skripsi STIA Yapls Blak Papua.

Widyastuti, Hana Chrysanti. 2008. Hubungan Antara Budaya Organisasi Dengan Komitmen Organisasi Pada Peerawat Rumah Sakit Panti Wilasa Citarum Semarang.

Amstrong. 1994. http://digilib.ump.ac.id/files/disk1/13/jhptump-a-galanganja-644-2babii.pdf.

Gilmer. Hasibuan. 1994. http://m31ly.wordpress.com/2010/06/05/kepuasan-kerja/

Husein. Umar. 1998. http://udinnotonegoroblog.blogspot.com

Jerris.1999.(http://jurnal-sdm.blogspot.com/2009/10/macam-gaya-kepemimpinan.html)

25.Oktober.2012

$\begin{array}{llll}\text { Potervdan } & \text { Steers. } & 1992 & \text { dalam }\end{array}$

(http://www.oocities.org/p3gi/VISI.html).Komitmen

organisasi.25.Oktober.2012.

RobIbins.2006:432.(muhamadbahrululum.blogspot.com/2012/04/kepemimpinan,pendah uluan,konsep.html)28.Juni.2012

Robbins dan Coutler. 2002. (http://jurnal-sdm.blogspot.com/2009/10/macam-gayakepemimpinan-kepemimpinan.html) 25.Oktober.2012.

Saydam.1996. Indikator-indikator Kedisiplinan (www.kumpulanblogger.com) 28 Juni 2012.

Yuwono.2005. (http://jurnal-sdm.blogspot.com/2009/09/indikator-untukmengukurkepuasan-kerja.html) 12 Juni 2012 